\title{
Using globally available soil moisture indicators for flood modelling in Mediterranean catchments
}

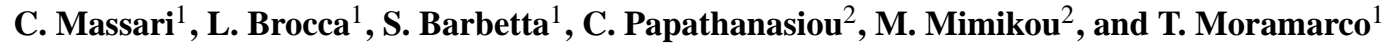 \\ ${ }^{1}$ Research Institute for Geo-Hydrological Protection, National Research Council, Perugia, Italy \\ ${ }^{2}$ Laboratory of Hydrology and Water Resources Management, National Technical University of Athens, Athens, Greece
}

Correspondence to: C. Massari (christian.massari@irpi.cnr.it)

Received: 23 July 2013 - Published in Hydrol. Earth Syst. Sci. Discuss.: 22 August 2013

Revised: 17 December 2013 - Accepted: 29 January 2014 - Published: 28 February 2014

\begin{abstract}
Floods are one of the most dangerous natural hazards in Mediterranean regions. Flood forecasting tools and early warning systems can be very beneficial to reducing flood risk. Event-based rainfall-runoff models are frequently employed for operational flood forecasting purposes because of their simplicity and the reduced number of parameters involved with respect to continuous models. However, the advantages related to the reduced parameterization oppose to the need of a correct initialization of the model, especially in areas characterized by strong climate seasonality. In this case, the use of continuous models could be desirable but it is very problematic in poorly gauged areas where continuous rainfall and temperature data are not available. This paper introduces a Simplified Continuous Rainfall-Runoff model (SCRRM), which uses globally available soil moisture retrievals to identify the initial wetness condition of the catchment, and, only event rainfall data to simulate discharge hydrographs. The model calibration involves only three parameters. For soil moisture, besides in situ data, satellite products from the Advanced SCATterometer (ASCAT) and the Advanced Microwave Scanning Radiometer for Earth observation (AMSR-E) sensors were employed. Additionally, the ERA-Land reanalysis soil moisture product of the European Centre for Medium-Range Weather Forecasting (ECMWF) was used.

SCRRM was tested in the small catchment of the Rafina River, $109 \mathrm{~km}^{2}$, located in the eastern Attica region, Greece. Specifically, sixteen recorded rainfall-runoff events were simulated by considering the different indicators for the estimation of the initial soil moisture conditions from in situ, satellite and reanalysis data. By comparing the performance of the different soil moisture products, we conclude
\end{abstract}

that: (i) all global indicators allow for a fairly good reproduction of the selected flood events, providing much better results than those obtained from setting constant initial conditions; (ii) the use of all the indicators yields similar results when compared with a standard continuous simulation approach that, however, is more data demanding; (iii) SCRRM is robust since it shows good performances in validation for a significant flood event that occurred on February 2013 (after calibrating the model for small to medium flood events). Due to the wide diffusion of globally available soil moisture retrievals and the limited number of parameters used, the proposed modelling approach is very suitable for runoff prediction in poorly gauged areas.

\section{Introduction}

In the context of climate change, in which runoff production mechanisms appear to be exacerbated by the modification of climatic variables, the flood frequency regime is altered and an increasing frequency of extreme events is to be expected. The Report of Intergovernmental Panel on Climate Change (IPCC, 2001) on potential effects of climate change highlights that "flood magnitude and frequency are likely (a $66-90 \%$ probability) to increase in most regions". Notwithstanding this issue, Europe seems to lack suitable and reliable procedures to promptly address the fundamental issues of flood-risk assessment and management. Even though several important laws and directives, both at national and at EU level, have been issued addressing this point, i.e. European Floods Directive 2007/60/CE, such legislative tools have not succeeded yet in effectively reducing the devastating and 
catastrophic effects of extreme flood events (Barredo, 2006). To this end, flood forecasting and early warning systems have been identified as fundamental tools for prevention and protection from flood risk.

The development of an early warning system for flood forecasting is particularly difficult for small- to mediumsized basins (area $<400 \mathrm{~km}^{2}$ ) for which the hydrologic response is extremely fast and an hourly (or finer) temporal resolution is required (Younis et al., 2008). To accomplish this task, a rainfall-runoff (RR) model able to simulate the runoff formation process (i.e. estimation of losses) and also the hydrological routing along hillslopes and channels has to be set up. Besides the spatial discretization (lumped versus distributed models) and the process description (physically based versus conceptual models), RR models applied for operational flood forecasting can be subdivided in two main categories: continuous and event-based (Brocca et al., 2011; Paquet et al., 2013). On the one hand, continuous RR models simulate the temporal evolution of the soil moisture (SM) conditions of the catchment, thus being able to model the complex interaction between rainfall and SM which is necessary to properly predict flood hydrographs (Camici et al., 2011). However, the different processes (infiltration, percolation, evapotranspiration, interception) involved in the simulation of the SM temporal evolution may require a large number of parameters to be identified. This could easily introduce significant uncertainties into the model prediction and non-identifiable problems (Beven, 2006). Moreover, continuous models require long-term and uninterrupted time series for the input data (at least rainfall and temperature) and this could be a strong limitation in many regions worldwide, mainly if hourly observations are needed (Viviroli et al., 2009). On the other hand, event-based RR models need a reduced parameterization, and they are easy to be applied, even from users without extended hydrological expertise, and require low computational effort. For that, these types of models are very appealing, and frequently employed within operational flood forecasting systems (Berthet et al., 2009; Coustau et al., 2012). The major limitations of event-based models lie in the definition of the initial SM conditions that could be very different from one storm event to another (Tramblay et al., 2012; Coustau et al., 2012, Van Steenbergen and Willems, 2013). This issue is particularly challenging in regions characterized by strong seasonality of the climate as it occurs in Mediterranean basins (Aronica and Candela, 2004).

Nowadays, several SM data sources are available, also on a global scale. Specifically, SM information can be obtained from in situ and satellite sensors or from land surface models. From in situ observations, it is worth mentioning the International Soil Moisture Network (Dorigo et al., 2011), an international cooperation to establish and maintain a global in situ SM database that can be used for global analysis, e.g. the validation of the retrieval algorithms applied to remotely sensed observations. Moreover, several satellite SM products are globally and freely available from active and passive microwave sensors, e.g. the Advanced SCATterometer (ASCAT) (Bartalis et al., 2007), the Advanced Microwave Scanning Radiometer for Earth observation (AMSR-E) (Owe et al., 2008), and the Microwave Imaging Radiometer with Aperture Synthesis (MIRAS) (Kerr et al., 2010). The accuracy and maturity of these satellite products have contributed to the implementation of a fully operational nearreal-time (NRT) SM processing chain for ASCAT (Wagner et al., 2013) from the European Organisation for the Exploitation of Meteorological Satellites (EUMETSAT) since December 2008. Finally, modelled SM data obtained from numerical weather prediction systems operated by international meteorological centres (e.g. the ECMWF, European Centre for Medium-Range Weather Forecasting) are also available on a global scale. As an example, in the framework of the implementation of EUMETSAT's H-SAF project (Satellite Application Facility on Support to Operational Hydrology and Water Management), an ASCAT root zone SM profile product has been developed based on ASCAT surface SM data assimilation into the ECMWF Land Surface Data Assimilation System (De Rosnay et al., 2013). All these SM data sets, which are globally available, might be potentially used for the initialization of event-based RR models in different catchments and regions worldwide, even for poorly gauged areas.

Some studies attempted to relate the RR model initial conditions with different external indicators of SM estimated by in situ, satellite and modelled data (Brocca et al., 2009a, b, 2011a; Tramblay et al., 2010, 2011, 2012; Beck et al., 2009; Coustau et al., 2012; Graeff et al., 2012). In situ data were employed in many studies investigating the relationship between SM and runoff (e.g. Penna et al., 2011; Matgen et al., 2012; Graeff et al., 2012), thus indirectly determining their potential use for RR modelling. Brocca et al. (2009a, 2011b) and Beck et al. (2009) used the SM products from ASCAT and AMSR-E for RR modelling in Italy, Luxembourg and Australia. However, the main purpose of these studies was to investigate the relationship between modelled and observed antecedent wetness conditions, without explicitly building a model that incorporates external SM data.

In this study, a Simplified Continuous RR Model (SCRRM) is proposed by exploiting SM provided by ground, satellite and reanalysis data. This new approach offers the advantages of continuous models, with the difference that the temporal evolution of SM over a long-term period is assessed by using SM directly from external sources, thus avoiding simulating processes such as evapotranspiration, evaporation and groundwater flow. The "observed" SM time series (i.e. those provided by external sources) are used to set the initial saturation conditions of the catchment within an eventbased model (Melone et al., 2001). In this way, the model is presented as "simplified continuous" since it links SM time series and a conceptual model for flood prediction. Doing so, the benefits of the event-based simulation, e.g. model 

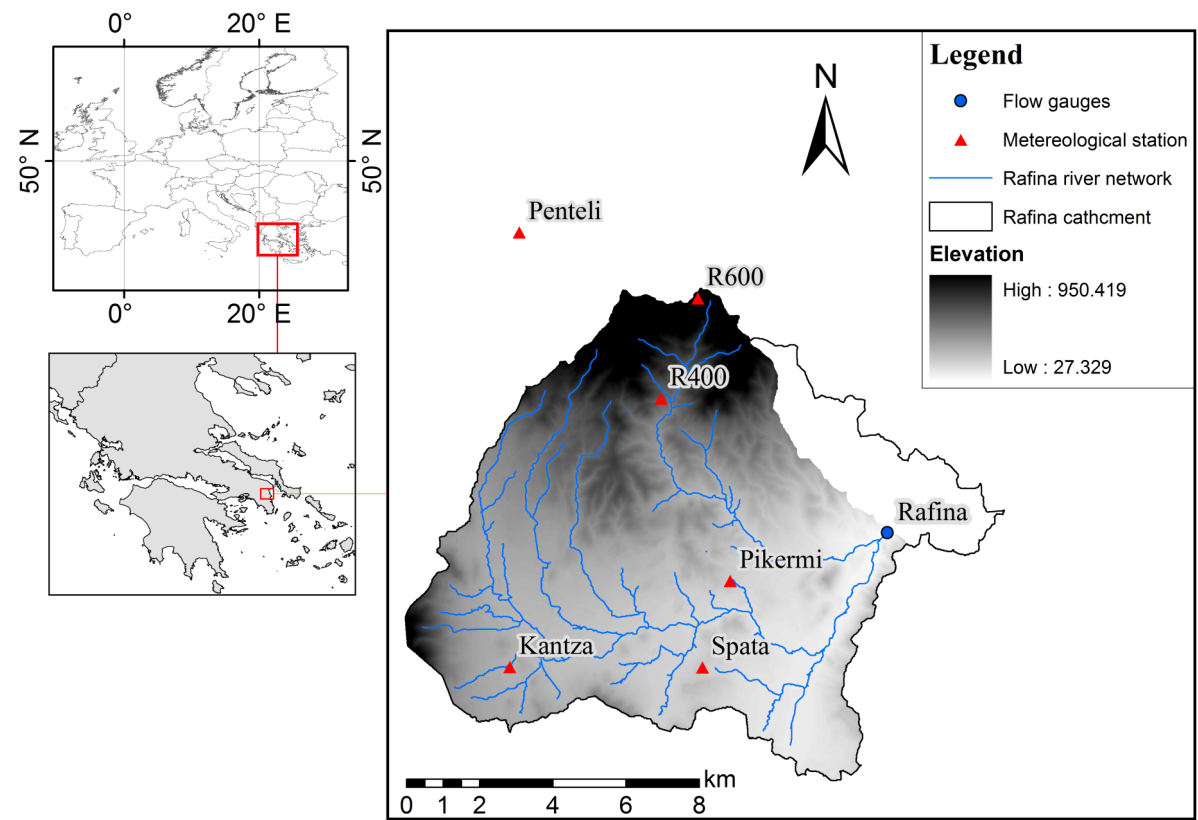

Fig. 1. Study area and locations of meteorological and runoff gauges stations used in the study.

parsimony, simplicity of use and no need for continuous rainfall and evapotranspiration data are achieved, while leaving the temporal evolution of the SM balance assessed by external sources. The results suggest that SCRRM can be particularly advantageous for operational purposes, especially in poorly gauged areas, where there is a lack of continuous meteorological data sets and a need to reduce the model parameterization, as well as to simplify the model structure in order to facilitate the model setup by end users (Montaldo et al., 2005; Coccia et al., 2009; Todini, 2009).

In the following, we first describe the study area (Rafina River basin, $109 \mathrm{~km}^{2}$, Greece), the meteorological data sets and the selected SM indicators to be used within SCRRM, then, besides the other models used (an event-based model and a standard continuous model) we describe the structure of SCRRM. In the results, we present both the comparison between in situ and the selected SM indicators used and the performance obtained from SCRRM compared to those obtained from the other models used in this study.

\section{Study area and data sets}

\subsection{Rafina catchment}

The study area is the Rafina river basin upstream from the Rafina gauged section $\left(109 \mathrm{~km}^{2}\right)$.

This is a periurban area in the greater southeast Mesogeia region in eastern Attica, Greece (Fig. 1). The area geographically extends from east of the Hymettus mountains to the coastline of Evoikos Gulf. The mean altitude of the region is $227 \mathrm{~m}$ a.s.l. (with the minimum altitude being 0 and the maximum $909 \mathrm{~m}$ a.s.1.). Ground slope ranges from 0 to $37.8 \%$ with a mean value of $7.5 \%$. Increased slopes and irregular terrain exist mainly at the upstream parts of the area. Attica has a typical subtropical Mediterranean climate, with prolonged hot and dry summers succeeded by considerably mild and wet winters. The mean annual precipitation is approximately $400 \mathrm{~mm}$, while snowfall is rare. Drought periods usually begin in May and last until October. The daily mean temperature ranges between $27^{\circ} \mathrm{C}$ during the summer months and $11^{\circ} \mathrm{C}$ during the winter months (Papathanasiou et al., 2013).

Geologically, the study area is part of the Attico-Cycladic Massif. The Neogene and Quaternary deposits fill up the degradations and tectonic grabens of the east Attica Basin and consist of alluvial deposits and Mio-pliocene lacustrine and terrestrial deposits, conglomerates, sand, marls, clayey material, marly limestones and clays (Jacobshagen, 1986). Rafina catchment is covered by different and often conflicting land uses. More specifically, it includes forests $(\sim 30 \%)$, arable soils and grasslands $(\sim 50 \%)$ mainly located upstream, and urban cells $(\sim 20 \%)$ located downstream (Alonistioti, 2011). The study area is under constantly increasing urbanization, its northern part is forested with flammable material and sediment load transfer and soil erodibility are intense (Papathanasiou et al., 2009, 2012).

\subsection{Hydro-meteorological data}

The Laboratory of Hydrology and Water Resources Management of the School of Civil Engineers of the National Technical University of Athens (NTUA) operates the Hydrological Observatory of Athens (HOA), a dense monitoring 
Table 1. Main characteristics of the selected rainfall-runoff events. $\theta_{\mathrm{e}}$ represents the in situ relative soil moisture at the beginning of each selected event.

\begin{tabular}{lrlrrrrc}
\hline Dates & $\begin{array}{r}\text { Maximum } \\
\text { discharge } \\
{\left[\mathrm{m}^{3} \mathrm{~s}^{-1}\right]}\end{array}$ & $\begin{array}{l}\text { Lag } \\
\text { time } \\
{[\mathrm{h}]}\end{array}$ & $\begin{array}{r}\text { Total } \\
\text { rainfall } \\
{[\mathrm{mm}]}\end{array}$ & $\begin{array}{r}\text { Direct } \\
\text { runoff } \\
{[\mathrm{mm}]}\end{array}$ & $\begin{array}{c}\text { Runoff } \\
\text { coefficient } \\
{[-]}\end{array}$ & $\begin{array}{r}\text { Duration } \\
{[\mathrm{h}]}\end{array}$ & $\begin{array}{c}\theta_{e} \\
\text { (in situ) } \\
{[-]}\end{array}$ \\
\hline 21 Mar 2009 & 3.5 & 2.9 & 14.6 & 0.3 & 0.02 & 22 & 0.43 \\
25 Oct 2009 & 10.7 & 3.8 & 27.8 & 1.3 & 0.04 & 25 & 0.22 \\
26 Oct 2009 & 4.0 & 3 & 12.3 & 0.3 & 0.03 & 19 & 0.33 \\
3 Nov 2009 & 4.4 & 4.1 & 21.0 & 0.3 & 0.02 & 24 & 0.38 \\
11 Dec 2009 & 12.4 & 4.0 & 34.8 & 1.8 & 0.05 & 24 & 0.52 \\
2 Jan 2011 & 3.3 & 5.5 & 18.5 & 0.2 & 0.01 & 30 & 0.40 \\
3 Feb 2011 & 39.5 & 5.4 & 87.5 & 10.7 & 0.12 & 40 & 0.49 \\
18 Feb 2011 & 7.5 & 4.1 & 12.5 & 0.6 & 0.04 & 19 & 0.42 \\
24 Feb 2011 & 18.8 & 5.2 & 47.2 & 5.8 & 0.12 & 37 & 0.58 \\
7 Mar 2011 & 5.5 & 5.0 & 17.0 & 0.8 & 0.05 & 26 & 0.48 \\
17 Apr 2011 & 2.9 & 4.1 & 12.7 & 0.2 & 0.02 & 23 & 0.22 \\
26 Apr 2011 & 5.0 & 5.8 & 28.6 & 1.0 & 0.04 & 37 & 0.27 \\
12 Jun 2011 & 9.3 & 4.4 & 28.2 & 1.1 & 0.04 & 19 & 0.31 \\
19 Dec 2011 & 6.7 & 8.5 & 18.8 & 1.0 & 0.05 & 35 & 0.09 \\
10 Jan 2012 & 2.5 & 9.2 & 15.0 & 0.7 & 0.05 & 39 & 0.34 \\
21 Feb 2013 & 137.2 & 4.6 & 107.1 & 14.5 & 0.13 & 38 & 0.67 \\
\hline
\end{tabular}

hydrometeorological network in the greater Athens area. HOA is the evolution from the METEONET network that has been operating since 2005 and consists of several active meteorological and active runoff measuring stations, properly located in the area. The stations are equipped with sensors that measure with 10-minute temporal resolution environmental parameters of hydrometeorological interest. Detailed information of the instruments can be found at https: //hoa.ntua.gr. Parallel to that, the National Observatory of Athens (NOA) also operates a dense meteorological network in the greater Athens area also recording valuable meteorological information in 10-minute temporal resolution (NOA, 2012, www.meteo.gr/meteosearch).

For this study, rainfall data were extracted from six rainfall stations of HOA and NOA networks (Fig. 1). As the area extends over only $109 \mathrm{~km}^{2}$, this number can be considered appropriate to take into account the spatial variability of rainfall in the catchment. Temperatures were retrieved from the thermometer located in Pikermi. Measured stages at the Rafina gauged site were used to develop updated rating curves and thus evaluate discharges at the locations of the gauge. The period of analysis ranges from 12 March 2009 to 28 February 2013. The main data analysis included a quality control to remove inconsistent values, and aggregation operations to produce hourly based time-step temporal resolution.

The rating curve developed for the Rafina site was based on velocity measurements carried out from the end of 2009 for low to medium water levels. It was assumed that (i) the instrument always worked under ideal conditions (as verified from the discharge data set), and, (ii) the geometry of gauging the cross-section was stable in time, even though some changes may have occurred during high flood events due to erosion, sediment transport and deposition. Based on that, it is likely that the rating curve contains inherent uncertainties, which may affect the estimated runoff coefficients. However, this is the best data available. Moreover, this issue extends beyond the main goal of the paper and it is expected to not affect the results since the same errors are present for all the investigated configurations.

The mean areal rainfall was calculated by the Inverse Distance Weighting Method. Direct runoff was evaluated as in Melone et al. (2002) by using an appropriate baseflow separation technique.

For this study, rainfall events were extracted by selecting those with a continuous rainfall characterized by a total rainfall larger than $10 \mathrm{~mm}$, and no rainfall in the preceding day. Eventually, 16 rainfall-runoff events were analysed with cumulated rainfall and runoff coefficients ranging from 12.3 to $107 \mathrm{~mm}$ and from 0.01 to $0.13 \mathrm{~mm}$, respectively (Table 1, Fig. 2). For the most significant event - occurring on 21 February 2013 - the maximum recorded peak discharge was $137.2 \mathrm{~m}^{3} \mathrm{~s}^{-1}$, while for the least intense event - recorded on 10 January 2012 - a peak discharge of $2.5 \mathrm{~m}^{3} \mathrm{~s}^{-1}$ was observed.

\subsection{Soil moisture indicators}

Four different SM indicators were selected covering the period 2009-2013. In particular, the selected indicators were (i) ground SM obtained from measurements carried out at a depth of $25 \mathrm{~cm}$ at Pikermi station (see Fig. 1); (ii) ASCATderived SM product (Wagner et al., 1999); (iii) AMSR-Ederived SM product (Owe et al., 2001); and (iv) ERA-Land 
Table 2. Soil moisture indicators used in this study.

\begin{tabular}{lccccccl}
\hline $\begin{array}{l}\text { Soil } \\
\text { moisture } \\
\text { indicator }\end{array}$ & LAT $^{1}$ & LON $^{2}$ & $\begin{array}{l}\text { Spatial } \\
\text { resolution }\end{array}$ & $\begin{array}{l}\text { Temporal } \\
\text { resolution }\end{array}$ & $\begin{array}{l}\text { Band } \\
{[\mathrm{GHz}]}\end{array}$ & $\begin{array}{l}\text { Retrieval } \\
\text { algorithm }\end{array}$ & $\begin{array}{l}\text { Depth } \\
{[\mathrm{cm}]}\end{array}$ \\
\hline \multicolumn{7}{c}{ Remote sensing soil moisture } \\
\hline In situ & 37.9919 & 23.9194 & N/A & 10 min & N/A & N/A & 25 \\
ERA-Land & 38.2406 & 23.3417 & $80 \mathrm{~km}$ & 1 day & N/A & N/A & $0-7,8-28$, \\
ASCAT & 37.9326 & 23.8872 & $25 \mathrm{~km}$ & $\approx 1$ day & $\begin{array}{l}5.25 \\
(\mathrm{C} \text { band })\end{array}$ & $\begin{array}{l}\text { WARP } 5.5 \\
\text { v1.1 }\end{array}$ & $0-3$ \\
AMSR-E & 37.875 & 23.875 & $56 \mathrm{~km}$ & $\approx 1$ day & $\begin{array}{l}6.90 \\
(\mathrm{C} \text { band })\end{array}$ & LPRM & $0-3$ \\
\hline
\end{tabular}

${ }^{1}$ LAT $=$ latitude, ${ }^{2}$ LON $=$ longitude.
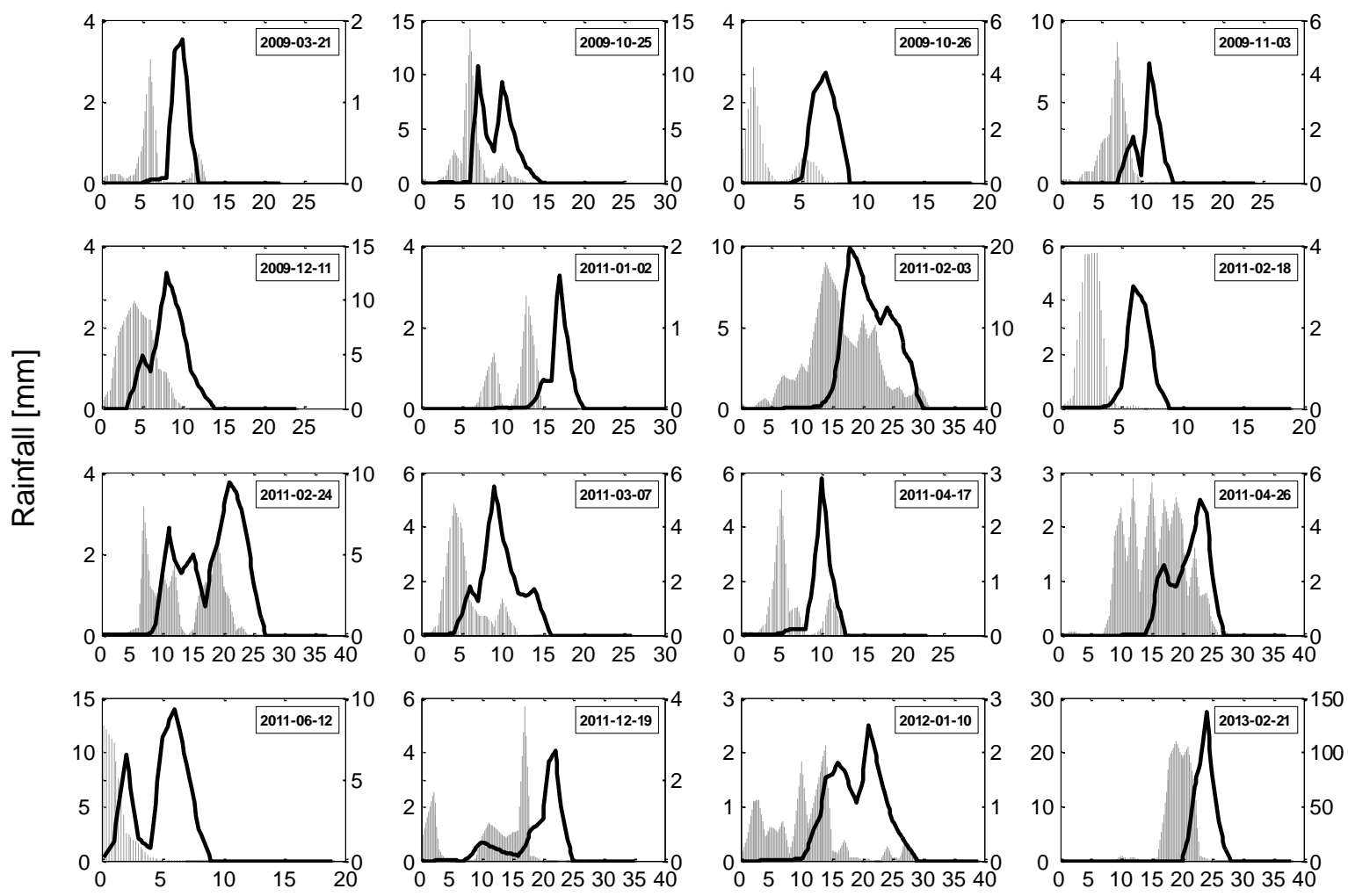

time $[\mathrm{h}]$

Fig. 2. Observed rainfall and discharge for the selected flood events.

SM product from the ECMWF (Balsamo et al., 2012). Given the catchment extension (about $100 \mathrm{~km}^{2}$ ) and the spatial resolution of the satellite (ASCAT and AMSR-E) and modelled (ERA-Land), products-only data of the pixel nearest to the centroid of the catchment were used and the corresponding relative surface SM time series were retrieved from the appropriate database, that is, no spatial aggregation was carried out. Moreover, pixels near the sea or in mountain areas were not considered. Table 2 summarizes the main characteristics of the selected soil moisture indicators.

\subsubsection{In situ soil moisture data}

SM data selected for this study were collected at Pikermi station (see Fig. 1). The station was installed at the beginning of 2009 from HOA and can be considered representative of the catchment in terms of land cover characteristics and soil 
properties. The sensor is a water content reflectometer Campbell Scientific CS616-L, installed in clay soil measuring volumetric SM at a depth of $25 \mathrm{~cm}$ through frequency domain reflectometry (FDR) technique. The measurements refer to the period from March 2009 to February 2013 and have a 10 -min temporal resolution. Since this station is the only one measuring SM within the catchment boundaries, it was assumed that measurements reflect the temporal variability of the soil moisture in the catchment.

\subsubsection{Satellite soil moisture: ASCAT and AMSR-E}

Remote sensing soil moisture products were retrieved from one active (ASCAT) and one passive sensor (AMSR-E). Both of them allow the retrieval of surface SM (SM representative of the first centimetres of the soil). In this section, after a description of each product we present the method for calculating the root zone SM from the remotely sensed surface SM.

ASCAT is a real-aperture radar instrument on board the MetOp satellite. It measures radar backscatter at C-band $(5.255 \mathrm{GHz})$ in $\mathrm{VV}$ polarization. Its spatial resolution is $25 \mathrm{~km}$ then re-sampled at $12.5 \mathrm{~km}$. In the study area, measurements are available at least once a day (07:00-08:00 UTC in descending orbit and/or 18:00-20:00 UTC in ascending orbit). The surface SM product (equivalent to a depth of $2-3 \mathrm{~cm}$ of the soil) is calculated from the backscatter measurements through a time-series-based change detection approach previously used for the ERS-1/2 by Wagner et al. (1999). The SM is derived by selecting the historical lowest and highest backscatter measurement to which is respectively assigned $0 \%$ (dry), and 100\% (wet) reference. The ASCAT surface SM product used for this study covers the period 2009-2013 considering both ascending and descending overpass.

The AMSR-E sensor is the instrument on board the NASA Aqua satellite. It is a passive microwave radiometer measuring at $6.9 \mathrm{GHz}$ (C-Band) and five higher frequencies. The sensor provided measurements from May 2002 to October 2011 with daily ascending and descending overpasses and a spatial resolution of about $56 \mathrm{~km}$ (resampled at $0.25^{\circ}$ ). In this study the Land Parameter Retrieval Model (LPRM) was used as a retrieval algorithm (Owe et al., 2001, 2008) on data for the period 2009-2011 (AMSR-E sensor stopped working in October 2011). The LPRM was developed by the University of Amsterdam (VU) in collaboration with NASA, and was successfully tested over many sites in Europe (e.g. Brocca et al., 2011c).

Remotely sensed products provide knowledge of soil moisture for a very thin surface layer $(\mathrm{ca} .0-5 \mathrm{~cm})$, however this is not sufficient for hydrological applications concerning RR transformation. Indeed, root-zone SM data are the main control parameters on the catchment response to a given storm event (Brocca et al. 2010). To obtain the root-zone SM product (SWI; soil water index) from the satellite-based surface observations, the semi-empirical approach developed by Wagner et al. (1999) was adopted. The recursive formulation of the method relies on (Albergel et al., 2012)

$\operatorname{SWI}\left(t_{n}\right)=\operatorname{SWI}\left(t_{n-1}\right)+K_{n}\left[m_{\mathrm{S}}\left(t_{n}\right)-\operatorname{SWI}\left(t_{n}-1\right)\right]$,

where $m_{\mathrm{S}}\left(t_{n}\right)$ is the surface SM observed by the satellite sensor, $\mathrm{SWI}_{t_{n}}$ is the soil wetness index representing the profileaveraged saturation degree and time $t_{n}$ is the acquisition time of $m_{\mathrm{s}}\left(t_{n}\right)$. The gain $K_{n}$ at time $t_{n}$ is given by (in a recursive form)

$$
K_{n}=\frac{K_{n-1}}{K_{n-1}+e^{-\left(\frac{t_{n}-t_{n-1}}{T}\right)},}
$$

where $T$ is the characteristic time length and represents the timescale of SM variation to obtain the SWI. For the initialization of this filter, $K_{1}$ and $\mathrm{SWI}_{1}$ were set to 1 and $m_{\mathrm{S}}\left(t_{1}\right)$, respectively (Albergel et al., 2012). The approach is also known as exponential filter. The reader can find a more detailed description of this approach in Wagner et al. (1999) and Albergel et al. (2012).

\subsubsection{ERA-Land soil moisture product (ECMWF)}

The ECMWF provides medium-range global forecasts for some environmental variables that include soil temperature, evaporation and SM. ERA-Land stems from ERA-Interim (Dee et al., 2011) for the atmosphere, however its land surface components were completely revised to match ECMWF most recent developments, e.g. the HTESSEL land surface model (Balsamo et al., 2012, 2013; Albergel et al., 2012). HTESSEL uses the dominant soil texture class from the FAO (FAO, 2003) data set for each grid point. Albergel et al. (2012) provide further details concerning the integration of the soil types into the ECMWF product.

The ERA-Land SM product used in this study ranges from 1 January 1979 to 31 December 2012 and is available for 00:00, 06:00, 12:00 and 18:00 UTC with a spatial resolution of about $80 \mathrm{~km}$ (T255) considering four layers of soil $(0-7,7-28,28-100$ and $100-289 \mathrm{~cm})$. In this study, the SM values relative to the first two layers $(0-28 \mathrm{~cm})$ were compared with in situ data, while the values of the first three soil layers $(0-100 \mathrm{~cm})$ were used for the RR transformation.

\section{Flood modelling}

In the following, we present a description of all the models used in this paper: an event-based model "Modello Idrologico Semidistribuito" (MISD, Melone et al., 2001), a continuous model (MISDc model " Modello Idrologico Semiditribuito in Continuo"; Brocca et al., 2011b) and the "Simplified continuous rainfall-runoff model", SCRRM, which might be viewed as an evolution of the previous two. It has to be pointed out that external sources of SM, i.e. from satellite, 
from in situ or from ERA-Land products, are used here as a proxy of observations for the assessment of the wetness state of the catchment (Beck et al., 2009; Brocca et al., 2009a, b).

\subsection{Event-based rainfall-runoff model: MISD}

The event-based RR model considered in this study is the lumped version of MISD.

\subsubsection{Losses}

MISD employs the Soil Conservation Service-Curve Number (SCS-CN) method for estimation of losses. The choice of the SCS-CN method is due to its wide use since 1980 (Kim and Lee, 2008) and its simplicity. In particular, for a storm event the partitioning of rainfall into runoff using the SCS$\mathrm{CN}$ method is based on the following equation:

$Q=\frac{\left(P-F_{\mathrm{a}}\right)^{2}}{P-F_{\mathrm{a}}+S} P \geq F_{\mathrm{a}}$,

where $F_{\mathrm{a}}$ is the initial abstraction, $S$ is the soil potential maximum retention estimated as a function of land use, hydrological soil group, and total precipitation of the previous five days; $Q$ is the direct runoff depth; and $P$ is the rainfall depth. The quantity $F_{\mathrm{a}}$ is considered linearly dependent on $S$ by

$F_{\mathrm{a}}=\lambda S$,

where $\lambda$ is the initial abstraction coefficient (Soil Conservation Service, 1993). Equation (1) is extended for the time evolution of the effective rainfall rate, $e(t)$, within a given storm as (Melone et al., 2001)

$e(t)=\frac{\mathrm{d} Q}{\mathrm{~d} t}=\frac{p(t)\left(P(t)-F_{\mathrm{a}}\right)\left(P(t)-F_{\mathrm{a}}+2 S\right)}{\left(P(t)-F_{\mathrm{a}}+S\right)^{2}} P(t) \geq F_{\mathrm{a}}$,

where $p$ is the rainfall rate and $P(t)=\int_{0}^{t} p(\tau) \mathrm{d} \tau$.

\subsubsection{Routing}

Once the time evolution of effective rainfall is computed, the routing to the outlet of the catchment is obtained from the convolution of the rainfall excess and the Geomorphological Instantaneous Unit Hydrograph (GIUH), such as proposed by Gupta and Waymire (1980). In the model, the lag time is evaluated through the relationship proposed by Melone et al. (2002)

$L=\eta 1.19 A^{0.33}$

with $L$ being the lag time (h), $A$ the area of the catchment $\left(\mathrm{km}^{2}\right.$ ), and $\eta$ a parameter to be calibrated (Moramarco et al., 2005).

To sum up, the parameters of MISD model are the lag-area relationship parameter, $\eta$, the initial abstraction coefficient, $\lambda$, and the soil potential maximum retention, $S$.

\subsection{Continuous rainfall-runoff Model: MISDc}

MISDc is a continuous rainfall-runoff model successfully applied to the Tiber River for flood prediction and operational purposes (http://www.cfumbria.it/MISDc/). The lumped version of MISDc model used in this study couples a soil water balance model (SWB, Brocca et al., 2008) to simulate the soil moisture temporal pattern, and MISD as an event-based RR model (MISD) for transferring the excess of the rainfall to the outlet section of the catchment. The two models are linked through an experimentally derived linear relationship between $S$ of the SCS method, and the relative soil moisture at the beginning of the event. The MISDc structure was established by analysing the hydrologic response of a small experimental catchment equipped with an automatic soil moisture monitoring system (Brocca et al., 2009a).

The SWB model is a simple bucket model representing the main processes needed for SM simulation: infiltration, percolation and evapotranspiration. More specifically, the processes are represented for infiltration through the GreenAmpt equation, for drainage by a gravity-driven non-linear relationship and for actual evapotranspiration by a linear relationship with the potential evapotranspiration, calculated through a modified Blaney and Criddle method. The reader is referred to Brocca et al. $(2008,2013)$ for the full description of the model equations. The SM simulated by the SWB is used to calculate the parameter $S$ of the SCS method by means of an experimentally derived relationship between $S$ and SM (Brocca et al. 2009a, b):

$S=a\left(1-\theta_{\mathrm{e}}\right)$,

where $\theta_{\mathrm{e}}$ is the modelled relative soil moisture at the beginning of the event and $a$ is a parameter to be estimated. Once the $S$ parameter is estimated, MISD is used for simulating the flood hydrograph (see Sect. 3.1.2).

MISDc requires as input rainfall and air temperature data; the model output is both the direct runoff hydrograph in correspondence to flood events and the catchment average relative soil moisture. In MISDc, seven parameters have to be estimated, namely the maximum water capacity of the soil layer $W_{\max }$, the saturated hydraulic conductivity $K_{\mathrm{s}}$, the ratio between the wetting front soil suction head and the soil layer thickness $\psi / L$, the pore size distribution index $m$, the correction coefficient for potential evapotranspiration $b$, the lag-area relationship parameter $\eta$, the initial abstraction coefficient $\lambda$ and the parameter $a$ of the $S-\theta_{\mathrm{e}}$ relationship (see Brocca et al., 2011b for further details).

\subsection{Simplified continuous rainfall-runoff model: SCRRM}

Continuous RR models like MISDc simulate SM to take the variability of the wetness conditions prior to a rainfall event into account. They require as input, continuously measured temperature or evapotranspiration and rainfall measurements 


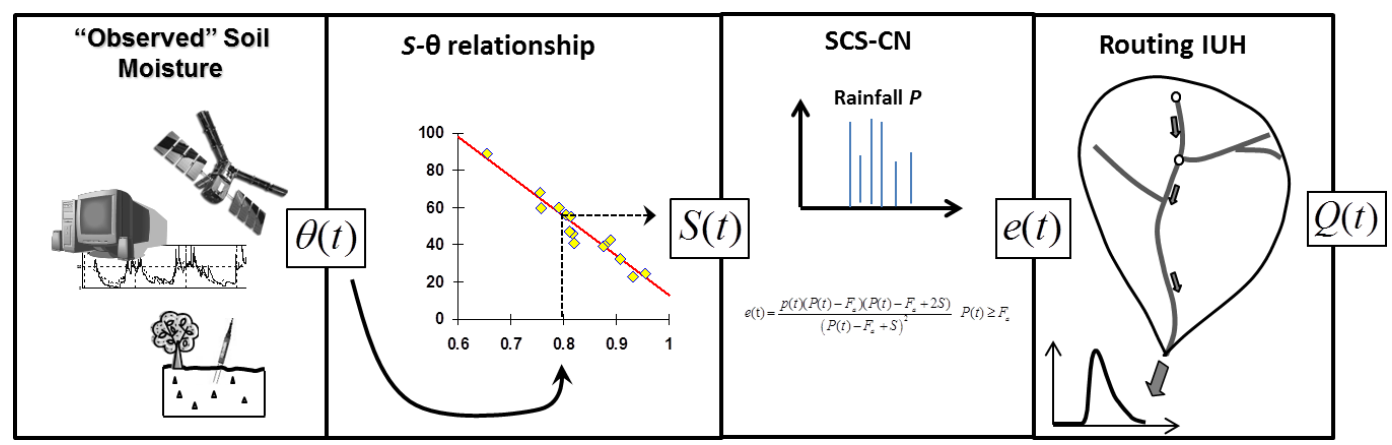

Fig. 3. Structure of the Simplified Continuous RR Model (SCRRM).

to model SM and produce the discharge hydrograph. If the $\mathrm{SM}$ at the beginning of an event is provided by an external indicator, e.g. in situ or globally available SM observations such as satellite and model-based reanalysis products, a new methodology approach can be derived, as schematized in Fig. 3. SCRRM is similar to a continuous model but with some significant differences. In particular, the temporal evolution of the soil wetness conditions of the catchment is not modelled from rainfall and temperature data like in MISDc but it is integrated directly into the model from SM observations (i.e. SWB is replaced in SCRRM by SM observations). Based on that, SCRRM uses SM indicators provided by external sources to infer the value of $S$ parameter for runoff determination. Like in MISDc, the model exploits the observed linear behaviour between the wetness state of the soil and the parameter $S$ of the SCS method (Brocca et al., 2009a, b) via Eq. (7). Once $S$ is known, the rainfall excess is calculated and transferred to the outlet section as in MISD (see Sect. 3.1.2).

In synthesis, the SCRRM proposed in this paper uses the $\mathrm{SM}$ and the event rainfall data as sole inputs to simulate hourly flood hydrographs. Since the SM is provided by an external indicator, the $S-\theta_{\mathrm{e}}$ relationship becomes a model relation embedded in the model structure and it is used to estimate the value of $S$ for the analysed events. The calibration of the model involves the following three parameters: the coefficient of initial abstractions $\lambda$, the parameter $a$ of the $S-\theta_{\mathrm{e}}$ relationship, and the parameter $\eta$ of the lag time-area relationship.

It has to be noted that the soil layer depth that controls the RR transformation is usually larger than few centimetres. As a result, the application of SCRRM with satellite products is taken into account by including as an additional parameter of SCRRM the characteristic time length $T$ of the exponential filter of Wagner et al. (1999) described in Sect. 2.3.2, or by considering the appropriate soil layer depth for the ERALand reanalysis product (see Sect. 2.3.3).

For this study, a lumped model was employed, even though the same concept can be easily applied to spatially distributed models. Finally, it is highlighted that the different components of the model (i.e. SCS-CN and GIUH) can be changed while keeping the general model structure shown in Fig. 3.

\subsection{Performance scores and data preparation}

\subsubsection{Performance in flood modelling}

For assessing the performance of the proposed models, the Nash-Sutcliffe efficiency coefficient (NS) was used to evaluate the agreement between the simulated and observed hydrographs for each one of the selected flood events (Table 1):

$\mathrm{NS}=1-\frac{\sum_{t=1}^{T_{\mathrm{ev}}}\left(Q_{\mathrm{obs}}-Q_{\mathrm{sim}}\right)^{2}}{\sum_{t=1}^{T_{\mathrm{ev}}}\left(Q_{\mathrm{obs}}-\bar{Q}_{\mathrm{obs}}\right)^{2}}$,

where $Q_{\text {obs }}$ and $Q_{\text {sim }}$ are the observed and simulated discharges at time $t$ respectively, $\bar{Q}_{\mathrm{obs}}$ is the mean value of the observed discharge during the event and $T_{\mathrm{ev}}$ is the event duration. In particular, as an objective function the mean NashSutcliffe, $\overline{\mathrm{NS}}$ was calculated as

$\overline{\mathrm{NS}}=\frac{\sum_{j=1}^{N_{\mathrm{ev}}} \mathrm{NS}_{j}}{N_{\mathrm{ev}}}$

and an hourly time step was used in the simulations. In Eq. (9) $N_{\mathrm{ev}}$ is the number of the events considered, whereas index $j$ refers to the event of Table 1. For model calibration, a standard gradient-based automatic optimization method ("fmincon" function in MATLAB ${ }^{\circledR}$ ) was used. In addition, to evaluate the performance of the model in reproducing flood events, the percentage error on peak discharge

$E_{Q_{\mathrm{p}}}=100 \frac{\max \left(Q_{\mathrm{obs}}\right)-\max \left(Q_{\mathrm{sim}}\right)}{\max \left(Q_{\mathrm{obs}}\right)}$

and the percentage error on direct runoff volume 


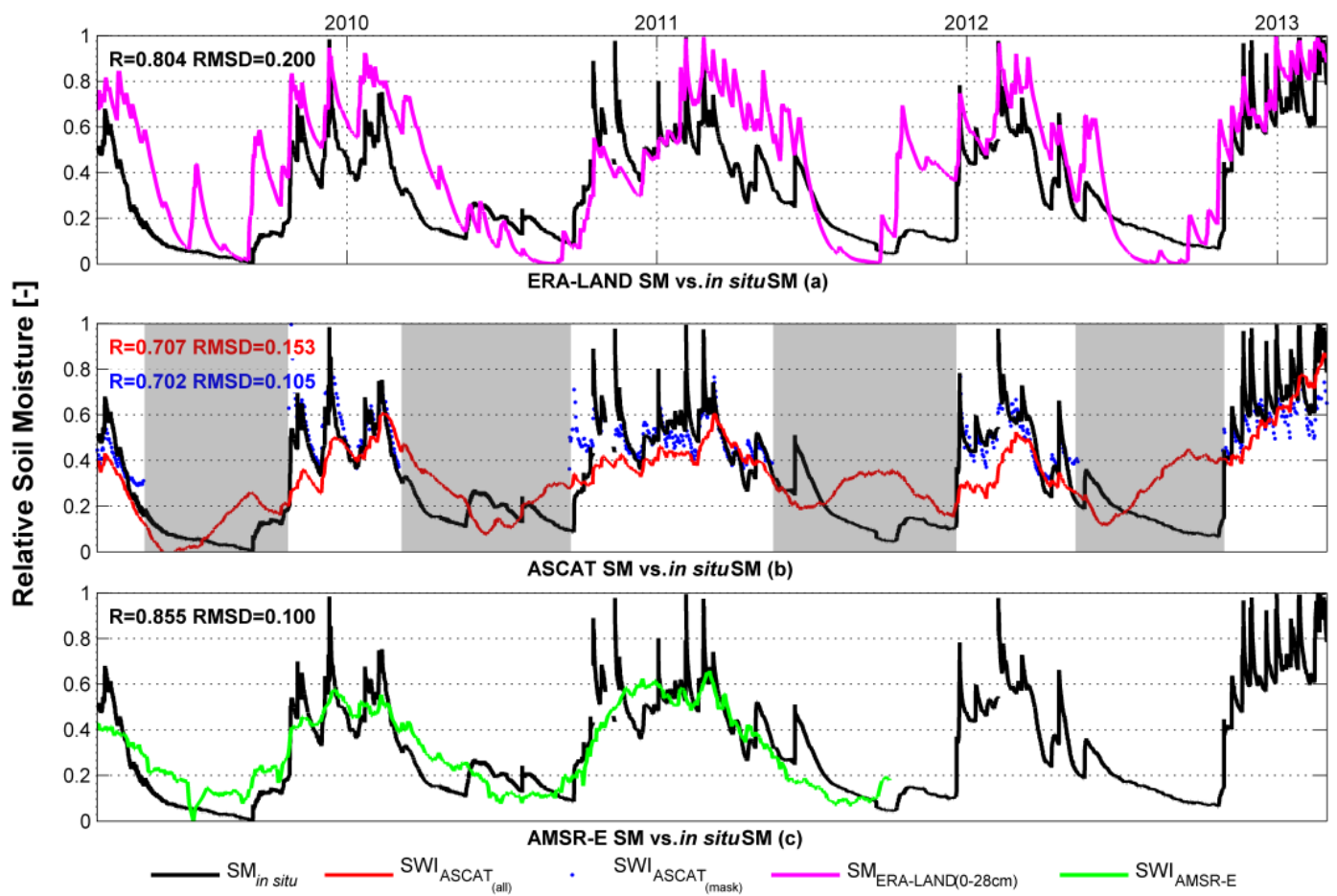

Fig. 4. Relative soil moisture temporal pattern for the different soil moisture indicators selected for this study (period March 2009February 2013). Comparison between the relative values of the ground soil moisture $\left(\mathrm{SM}_{\mathrm{in}}\right.$ situ $)$ obtained from measurements carried out at a depth of $25 \mathrm{~cm}$ (number of data, $N=34972$ hourly data) with (a) ERA-Land soil moisture product from ECMWF (SMERA-LAND(0-28cm) obtained from the weighted mean of the $0-7$ and $7-28 \mathrm{~cm}$ products $(N=1450)$; (b) SWI ASCAT-derived soil moisture product considering the whole data set ( $\mathrm{SWI}_{\mathrm{ASCAT}(\mathrm{all})} N=1326, T=147.5$ days) and the data set with data in shaded windows removed (SWI ASCAT(mask) , $N=631, T=9.5$ days); (c) AMSR-E-derived soil moisture product ( $\mathrm{SWI}_{\mathrm{AMSR}-\mathrm{E}}, T=7.5$ days; $N=584$ ). $R$ refers to the correlation coefficient, RMSD are the root mean squared differences.

$E_{\mathrm{V}}=100 \frac{\sum_{t}^{T_{\mathrm{ev}}} Q_{\mathrm{obs}}-\sum_{t}^{T_{\mathrm{ev}}} Q_{\mathrm{sim}}}{\sum_{t}^{T_{\mathrm{ev}}} Q_{\mathrm{obs}}}$

were both evaluated for each single event and as a mean of all the selected events.

\subsubsection{SM data preparation}

ASCAT SM is given in percentage (index between 0 and 100) while AMSR-E, in situ and ERA-Land data are in $\mathrm{m}^{3} \mathrm{~m}^{-3}$, therefore, to allow for a robust comparison and a homogenous parameter calibration, all soil moisture data sets (in situ, remotely sensed and modelled) were rescaled between $[0,1]$ using their own maximum and minimum values over the period of analysis. The evaluation of satellite and re-analysis SM data against in situ observations was carried out using the correlation coefficient, $R$, and the root mean squared differences (RMSD) as in Brocca et al. (2011c).

\section{Results and discussions}

\subsection{Assessment of the soil moisture indicators}

Figure 4 compares the relative values of the ground SM $\left(\mathrm{SM}_{\mathrm{in} \text { situ }}\right)$ obtained from measurements carried out at a depth of $25 \mathrm{~cm}$ with (i) ERA-Land SM product from ECMWF, obtained from the weighted mean of the $0-7$ and $7-28 \mathrm{~cm}$ soil layers, (Fig. 4a); (ii) ASCAT-derived SWI product (Fig. 4b); and (iii) AMSR-E-derived SWI product (Fig. 4c). Data refer to the period March 2009-February 2013.

ERA-Land (Fig. 4a), is satisfactorily correlated with in situ data $(R=0.804)$ but it shows higher RMSD with respect to the other products, $(\mathrm{RMSD}=0.200)$ likely due to its coarse spatial resolution $(\sim 80 \mathrm{~km})$ and to errors in the meteorological forcing (mainly precipitation) that are obtained directly from the global model and not from ground observations.

For remotely sensed SM indicators (Figs. 4b, c), the evaluation of SWI data was obtained from maximizing the correlation coefficient $R$ by varying the $T$ parameter of the exponential filter from 1 to 200 days at step of 0.5 days. For ASCAT, an anomalous behaviour was observed in dry periods which involved an anomalous increase without the occurrence of 
rainfall (see shaded areas in Fig. 3b). Such behaviour has been observed in other arid and semi-arid regions as well, and it is assumed to be due to volume-scattering effects from dry sub-surface soil layers (Wagner et al., 2013). Given that to date there is no solution to this problem, the analysis was carried out twice: once by considering the whole data set $\left(\mathrm{SWI}_{\mathrm{ASCAT}(\text { all })}\right.$ in red in Fig. 4b) and once with removed anomalous data ( $\mathrm{SWI}_{\mathrm{ASCAT} \text { (mask) }}$ in blue in Fig. $4 \mathrm{~b}$ ). In the first case the parameter $T$ is 147.5 days with a correlation coefficient $R=0.707$ and $\mathrm{RMSD}=0.153$, whereas without anomalous data $T=9.5$ days, $R=0.702$ and $\mathrm{RMSD}=0.105$. While the first result conflicts with the results of Wagner et al. (1999), Ceballos et al. (2005) and Brocca et al. (2011c), the second one is more similar to the studies of Wagner et al. (1999) which found $T$ equal to 20 days for an area of about $600000 \mathrm{~km}^{2}$ in the Ukraine. Therefore, in what follows, only the ASCAT data set without anomalous data is considered. For AMSR-E product (Fig. 4c), $T=7.5$ days with $R=0.855$ and $\mathrm{RMSD}=0.100$. In this case, the lower values of $T$ are due to the smoother behaviour of the AMSRE SM product with respect to ASCAT SM.

Overall, both ERA-Land and satellite products show good correlation $(R>0.7)$ with in situ data. For satellite products, apart from the scattering problem described for ASCAT in dry periods, such good correlations exclude problems due to vegetation cover (Owe et al., 2008; Wagner et al., 2013)

\subsection{Model performances}

In the following, the performances of SCRRM and MISDc are presented for a simple split sample test procedure. The model parameters were calibrated on the first eight flood events (from 24 March 2009 to 18 February 2011), whereas the remainder of them (from 24 February 2011 to 21 February 2013) was used in validation. The results obtained with MISDc are used as a baseline to assess the consistency and the reliability of SCRRM. Table 3 summarizes the value of the parameters obtained for all the models used in this study.

\subsubsection{MISD using "observed" initial conditions}

As a first analysis, to assess the optimal antecedent wetness conditions for the selected events, the soil potential maximum retention, $S$, was expressed by using observed rainfall and direct runoff depth by inverting Eq. (3) as in Beck et al. (2009) and Brocca et al. (2009a). That is, $S$ is the value of the potential maximum retention that reproduces the direct runoff volume, henceforth it is indicated as "observed $S^{\prime \prime}, S_{\text {obs }}$ (Brocca et al., 2011b).

The calibration of the model was carried out by maximizing $\overline{\mathrm{NS}}$ for estimating at the same time as $\lambda, \eta$ and $S_{\text {obs }}$. The value of the parameters obtained in calibration is $\lambda=0.0015$ and $\eta=0.669$ (Table 3 ), while $S_{\text {obs }}$ ranges from 254 to $1188 \mathrm{~mm}$ (see Table 4), indicating a wide range of initial conditions at the beginning of the events. In calibration,
Table 3. Calibrated parameters of the models used in the study obtained from the maximization of the mean NS among all the events. MISD Sobs $=$ MISD using "observed" initial condition $S_{\text {obs }}$ (obtained from inverting Eq. 3); MISD $_{\text {Scost }}=$ MISD model using constant observed initial conditions (equal to the mean of $S_{\text {obs }}$ among all the selected events); in situ=model SCRRM using $S$ estimated from in situ SM measurements; ASCAT = SCRRM using $S$ estimated from ASCAT SM measurements; AMSR$\mathrm{E}=\mathrm{SCRRM}$ using $S$ estimated from AMSR-E SM measurements; ERA-Land $=$ SCRRM using $S$ estimated from ERA-Land SM measurements; MISDc $=$ MISDc model (only $a, \eta$ and $\lambda$ are shown).

\begin{tabular}{lcccc}
\hline Model & $\begin{array}{c}a \\
{\left[\mathrm{~mm}^{-1}\right]}\end{array}$ & $\eta$ & $\lambda$ & $T$ \\
\hline MISD $_{\text {Sobs }}$ & & 0.669 & 0.0015 & - \\
MISD $_{\text {Scost }}$ & - & 0.349 & 0.0010 & - \\
In situ & 1254 & 0.643 & 0.0010 & - \\
ASCAT & 1250 & 0.645 & 0.0010 & 168.3 \\
AMSR-E & 1250 & 0.647 & 0.0021 & 120.0 \\
ERA-Land & 1057 & 0.634 & 0.0023 & - \\
MISDc & 1184 & 0.650 & 0.0010 & - \\
\hline
\end{tabular}

NS values range from 0.35 to 0.84 , with a mean value of 0.61 , indicating an acceptable fit of the model. Due to the low reliability of the estimated rating curve as well as the weak response of the catchment to rainfall inputs in terms of runoff, for low-magnitude flood events, the peak discharges are usually overestimated. Indeed, a successful application of whatever rainfall-runoff model to this area may be very difficult since the contribution of the rainfall to runoff is very small (see the low runoff coefficients in Table 1). However, these have to be considered the best possible results that can be attained for this catchment since the initial conditions are derived from observed values of rainfall and discharge.

Theoretically, in validation, $S_{\text {obs }}$ cannot be calibrated since discharge values are unknown. However, aiming only to have a baseline for comparing the performances obtained from the other models, the parameters obtained in calibration were used to predict the last eight events assuming $S_{\text {obs }}$ as known (i.e. best initial condition estimation). The results are presented in Table 4 and show performances very similar to those obtained in calibration.

\subsubsection{MISD using constant initial conditions}

If an event-based RR model is run without the knowledge of the initial conditions, a constant value for all the events has to be selected. To highlight this situation, in the calibration period the initial condition for all the selected flood events was set equal to the mean of $S_{\text {obs }}(659.1 \mathrm{~mm}$ in Table 4 for the flood events of the calibration period). The values of $\lambda$ and $\eta$ parameters obtained in calibration are given in Table 3. In this case, mean and median NS is equal to 0.04 and 0.13 , respectively (Table 4). In validation, mean $S_{\text {obs }}$ was set equal to $451.04 \mathrm{~mm}$ (see Table 4 , mean of the $S_{\text {obs }}$ of the flood 
Table 4. Performance of the models used in the study in terms of Nash-Sutcliffe coefficient NS. $S_{\text {obs }}$ refers to "observed" soil potential maximum retention determined by using observed rainfall and direct runoff depth; MISD $_{\text {Sobs }}=$ NS obtained from MISD using $S_{\text {obs }}$; MISD $_{\text {Scost }}=$ NS obtained from MISD using constant observed initial conditions (equal to the mean of $S_{\text {obs }}$ among all the selected events); in situ = NS obtained from SCRRM using $S$ estimated from in situ SM measurements; ASCAT = NS obtained from SCRRM using $S$ estimated from ASCAT SM measurements; ERA-LAND = NS obtained from SCRRM using $S$ estimated from ERA-Land SM measurements; AMSR-E = NS obtained from SCRRM using $S$ estimated from AMSR-E SM measurements; MISDc = NS obtained from MISDc. Numbers in brackets in the validation period refer to the statistics calculated for the flood events for the period 24 February 2011 to 12 June 2011 (the only available for ASCAT).

\begin{tabular}{|c|c|c|c|c|c|c|c|c|}
\hline Dates & $\begin{array}{r}S_{\mathrm{obs}} \\
(\mathrm{mm})\end{array}$ & MISD $_{\text {Sobs }}$ & MISD $_{\text {Scost }}$ & In situ & ASCAT & AMSR-E & ERA-Land & MISDc \\
\hline \multicolumn{9}{|c|}{ Calibration } \\
\hline 21 Mar 2009 & 653.3 & 0.40 & -0.04 & 0.40 & 0.40 & 0.43 & 0.43 & 0.28 \\
\hline 25 Oct 2009 & 543.3 & 0.57 & 0.64 & 0.40 & 0.36 & 0.34 & 0.43 & 0.37 \\
\hline 26 Oct 2009 & 372.0 & 0.35 & 0.20 & 0.12 & 0.06 & 0.06 & 0.10 & 0.08 \\
\hline 3 Nov 2009 & 1051.2 & 0.68 & -0.83 & 0.60 & 0.67 & 0.68 & 0.56 & 0.68 \\
\hline 11 Dec 2009 & 599.1 & 0.84 & 0.84 & 0.87 & 0.86 & 0.73 & 0.87 & 0.76 \\
\hline 2 Jan 2011 & 1187.5 & 0.64 & -1.30 & 0.48 & 0.49 & 0.29 & 0.64 & 0.52 \\
\hline 3 Feb 2011 & 612.5 & 0.80 & 0.79 & 0.80 & 0.79 & 0.82 & 0.78 & 0.79 \\
\hline 18 Feb 2011 & 253.9 & 0.59 & 0.06 & 0.19 & 0.23 & 0.38 & 0.33 & 0.35 \\
\hline Mean & 659.0 & 0.61 & 0.04 & 0.48 & 0.48 & 0.47 & 0.52 & 0.48 \\
\hline Median & 605.8 & 0.62 & 0.13 & 0.44 & 0.45 & 0.41 & 0.50 & 0.44 \\
\hline Max & 1187.5 & 0.84 & 0.84 & 0.87 & 0.86 & 0.82 & 0.87 & 0.79 \\
\hline Min & 253.9 & 0.35 & -1.30 & 0.12 & 0.06 & 0.06 & 0.10 & 0.08 \\
\hline \multicolumn{9}{|c|}{ Validation } \\
\hline 24 Feb 2011 & 330.4 & 0.84 & 0.81 & 0.69 & 0.68 & 0.82 & 0.82 & 0.77 \\
\hline 7 Mar 2011 & 323.8 & 0.81 & 0.45 & 0.44 & 0.63 & 0.80 & 0.81 & 0.79 \\
\hline 17 Apr 2011 & 646.5 & 0.23 & -0.54 & 0.16 & 0.18 & 0.04 & 0.16 & 0.20 \\
\hline 26 Apr 2011 & 718.9 & 0.77 & 0.49 & 0.70 & 0.64 & 0.42 & 0.67 & 0.74 \\
\hline 12 Jun 2011 & 329.9 & 0.53 & -0.04 & 0.18 & 0.08 & 0.32 & 0.34 & 0.27 \\
\hline 19 Dec 2011 & 302.1 & 0.53 & -0.08 & 0.09 & 0.23 & - & 0.18 & 0.11 \\
\hline 10 Jan 2012 & 289.9 & 0.46 & 0.15 & 0.09 & 0.13 & - & 0.11 & 0.03 \\
\hline 21 Feb 2013 & 670.0 & 0.85 & 0.39 & 0.82 & 0.83 & - & 0.49 & 0.85 \\
\hline Mean & 451.04 & $0.63(0.63)$ & $0.20(0.23)$ & $0.40(0.43)$ & $0.43(0.48)$ & $(0.47)$ & $0.45(0.56)$ & $0.47(0.55)$ \\
\hline Median & 330.15 & $0.65(0.76)$ & $0.27(0.45)$ & $0.31(44)$ & $0.43(0.62)$ & $(0.41)$ & $0.42(0.67)$ & $0.51(0.74)$ \\
\hline Max & 718.9 & $0.85(0.84)$ & $0.81(0.81)$ & $0.82(0.70)$ & $0.83(0.68)$ & $(0.82)$ & $0.82(0.82)$ & $0.85(0.79)$ \\
\hline Min & 289.9 & $0.23(0.23)$ & $-0.54(-0.54)$ & $0.09(0.16)$ & $0.08(0.08)$ & $(0.04)$ & $0.11(0.16)$ & $0.03(0.20)$ \\
\hline
\end{tabular}

events of the validation period) obtaining results similar to those achieved in calibration with poor prediction skills of the model. Overall, these results highlight the importance of a correct selection of the initial condition for flood modelling in this catchment.

\subsubsection{SCRRM and MISDc models}

In the following, the performances of SCRRM and MISDc models are presented and compared for the selected calibration and validation periods. In particular, SCRRM was run by considering in situ, ASCAT, AMSR-E and ERA-Land SM data sets with the value of the SM at the beginning of the event picked up directly from time series by selecting the $\mathrm{SM}$ value corresponding to the preceding date nearest to the event date. For ASCAT, only the results with removed anomalous data are presented. For AMSR-E, the validation was carried out for only five events (from 24 February 2011 to 12 June 2011, the results of this set of events for the other SM indicators are presented in brackets) since for the last three events AMSR-E SM was not available (AMSR-E sensor ceased working on October 2011). The calibration of both models was carried out by maximizing $\overline{\mathrm{NS}}$. The calibrated values of the parameters are presented in Table 3. Note that for the two satellite products the characteristic time length $T$ was also calibrated as specified in Sect. 3.3. For MISDc, only the parameters in common with SCRRM are shown. Table 4 summarizes the results in terms of NS for calibration and validation. 

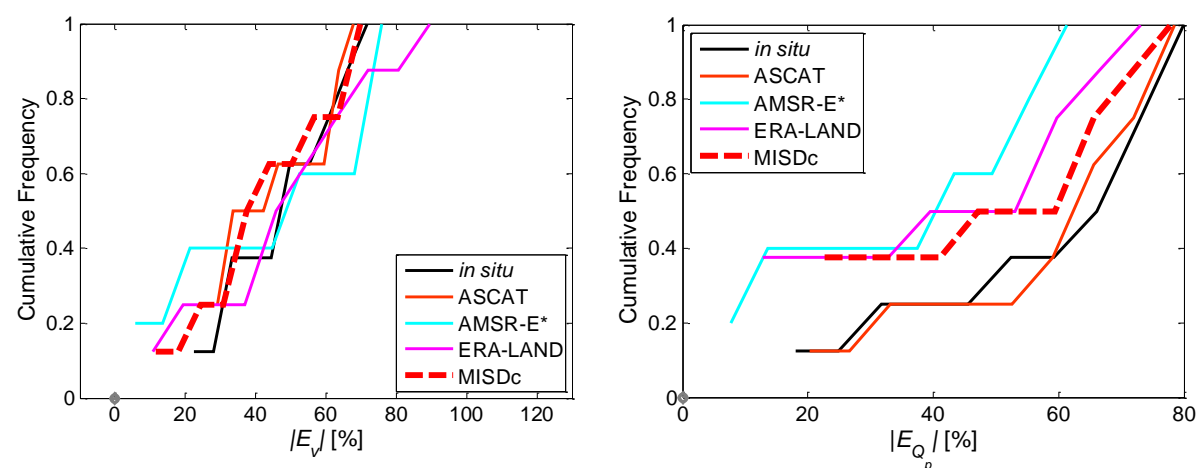

Fig. 5. Cumulative frequency of absolute error in volume $\left|E_{\mathrm{v}}\right|(\mathbf{a})$, and absolute error in peak discharge, $\left|E_{Q_{\mathrm{p}}}\right|$ (b). (a) was obtained from the validation of the events from 24 February 2011 to 21 February 2013, and (b) using SCRRM with the initial condition calculated with in situ data (in situ), with ASCAT data (ASCAT), AMSR-E data (AMSR-E) and with ERA-Land data (ERA_LAND). MISDc refers to the use of "Modello Idrologico Semidistribuito in continuo (Brocca et al., 2011b). * Results for AMSR-E refer to only five events (AMSR-E sensor ceased to work on October 2011).

NS values obtained from the calibration of SCRRM using in situ SM data range from 0.12 to 0.80 with $\overline{\mathrm{NS}}=0.48$. The calibration was also carried out to take into account the soil layer depth influence on the RR transformation by using the parameter $T$ as it was done for the two satellite products. In this case, the results only showed a little improvement and are not presented here for the sake of brevity. For ASCAT and AMSR-E, $\overline{\mathrm{NS}}$ is equal to 0.48 and 0.47 and median NS is equal to 0.45 and 0.41 , respectively. Note that in this case, the calibrated values of $T$ (168.3 and 120 days for ASCAT and AMSR-E, respectively, see Table 3) are much higher than the ones presented in Sect. 4.1. These results are consistent with those of (Brocca et al., 2010) which highlighted an influence of a deep soil layer in the RR transformation process. For ERA-Land SM used in SCRRM, NS ranges from 0.10 to 0.87 with a mean of 0.52 . The SM in this case was calculated by considering the weighted mean of the three SM available layers $(0-7,0-28,28-100 \mathrm{~cm})$ because it yielded better results with respect to the first two layers. For MISDc the performance in calibration is similar to the ones obtained from SCRRM, with NS ranging from 0.08 to 0.79 and mean NS equal to 0.48 .

Overall, in terms of mean NS, the performance scores of SCRRM are encompassed in the ones obtained by using MISD with observed initial conditions, and those considering a constant $S$. Moreover, they are similar to those of MISDc. More significant events (e.g. 11 December 2009, 3 February 2011, 2 January 2011), which are critical for flood forecasting, yield better results for all the selected indicators.

In validation, the results in terms of mean and median NS for SCRRM show a slight deterioration of the performances. The two satellite products perform in a quite similar way when choosing the same number of events, whereas the results of ERA-Land are comparable with those obtained through MISDc. Figure 5a, b plots the cumulative frequency of the absolute error in volume, $E_{\mathrm{V}}$, and in peak discharge,
$E_{Q_{\mathrm{p}}}$, obtained in validation, respectively. For $E_{\mathrm{V}}$, all products and MISDc show the same performances whereas, when considering $E_{Q_{\mathrm{p}}}$, ERA-Land shows better scores with respect to ASCAT and in situ data.

To sum up, in validation SCRRM gives results similar to MISDc, with ERA-Land SM slightly overperforming the satellite products in terms of NS and $E_{Q_{\mathrm{p}}}$. In situ data, which are based on soil moisture measurements at a depth of $25 \mathrm{~cm}$, have a behaviour similar to the other indicators both in terms of mean NS and $E_{\mathrm{V}}$ (Fig. 5a), but worse results in terms of median $E_{Q_{\mathrm{p}}}$ (Fig. 5b).

\subsubsection{Event of 21 February 2013}

The event of 21 February 2013 is particularly interesting for the area since it is one of the largest recorded at the Rafina gauged site since the installation of the gauge. As a result, it is particularly useful in assessing the robustness of the SCRRM model given that the model was calibrated for small to medium events. Unfortunately, for this event only SM from ASCAT, in situ, and ERA-Land was available (not from AMSR-E). Figure 6 shows the observed and predicted flood hydrograph for such an event obtained from SCRRM using SM from in situ, ASCAT and ERA-Land data (using the parameter calibrated on the first eight events and shown in Table 3) as well as results obtained from MISDc. As it can be seen, results are good using SCRRM with in situ and ASCAT data: NS is equal to 0.85 and $0.78, E_{Q_{\mathrm{p}}}$ is equal to -14.5 and $-12.3 \%$ and $E_{\mathrm{V}}$ is equal to 52.2 and $48 \%$, respectively. ERA-Land slightly overestimates the peak discharge with $E_{Q_{\mathrm{p}}}=9.5 \%$ but yields larger errors in NS $=0.49$ and in volume $E_{\mathrm{V}}=93.8 \%$ probably due to an overestimation of the initial SM conditions. Eventually, results are in line with MISDc which yields NS $=0.82$ and $E_{Q_{\mathrm{p}}}=-20.5 \%$. 


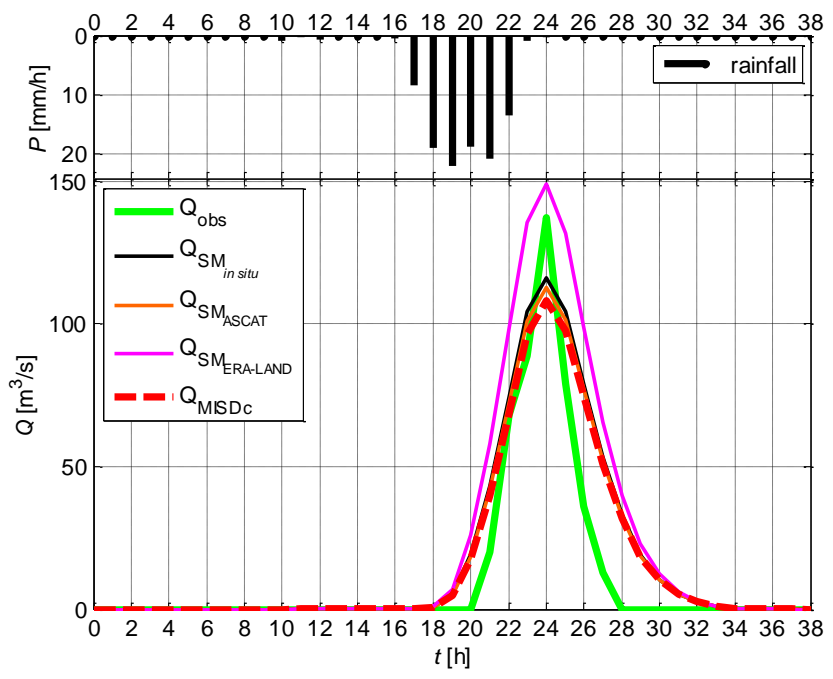

Fig. 6. Validation of the event of 21 February 2013 at the Rafina gauged site. Comparison between observed $Q_{\mathrm{obs}}$ and predicted flood hydrographs using SCRRM with in situ data $\left(Q_{\mathrm{SM}_{\mathrm{in} \mathrm{situ}}}\right)$, ASCAT data $\left(Q_{\text {SMASCAT }}\right)$, ERA-Land data $\left(Q_{\text {SM-ERA-LAND }}\right)$ and $\operatorname{MISDc}\left(Q_{\text {SM-MISDc }}\right)$.

\section{Conclusions}

A Simplified Continuous RR Model (SCRRM) has been developed to simulate discharge hydrographs in a small Greek catchment located in the Attica region. The model uses globally available soil moisture as a proxy of the wetness state of the catchment and event rainfall data (i.e. continuous rainfall time series are not needed) to simulate hourly discharge hydrographs. In the proposed model, the soil moisture provided by an external indicator is used to infer the initial condition through a linear experimental relationship previously studied by Brocca et al. (2009a, b). This new modelling approach keeps the advantages of event-based RR models but also overcomes the issues related to the selection of a proper initial condition.

Different SM indicators were used within SCRRM and compared in terms of flood hydrographs prediction (in situ, ASCAT, AMSR-E, and ERA-Land data) and against the outcomes of a continuous model. The model robustness was successfully tested by a split sample test procedure. Despite the inherent uncertainties in the available rating curve, it was found that

1. SCRRM model satisfactorily reproduces the selected flood events with performances comparable with those obtained from a continuous simulation approach (i.e. MISDc);

2. all the selected indicators work well, with the ERALand product slightly overperforming (on average) in situ and satellite products;
3. satellite products perform similar to each other, yielding results comparable with those obtained from MISDc. Particularly for ASCAT, an anomalous behaviour (already observed in several arid and semi-arid regions) was observed in dry periods, which involved an anomalous increase of the soil moisture despite the absence of rainfall;

4. SCRRM is robust since it provides good performance in validation for one of the most significant events recorded at the Rafina gauged site, which occurred on February 2013 (based on calibrated parameters obtained for small to medium magnitude events).

Overall, the similarity of the performance between SCRRM and a standard continuous simulation approach recommend the use of global available products to overcome the lack of ground data for hydrological applications in many areas of Europe. Moreover, the limited number of parameters used by the model along with the ever-increasing availability of globally available soil moisture data sets necessitates a greater effort in research for the applicability of the model for operational flood forecasting purposes to poorly gauged sites of the Mediterranean areas. Future studies need to assess the performance of the model in other catchments to support these conclusions.

Acknowledgements. This research has been carried out under the Project FLIRE "FLoods and fIre Risk assessment and managEment". The project aims to develop a warning system for floods and fire risk management and is co-financed by European Commission General Directorate for the Environment, LIFE financial instrument with $50 \%$. The authors wish to thank NOA (National Observatory of Athens) and HOA (Hydrological Observatory of Athens) for providing the analysed data for the Rafina river basin, and Gianpaolo Balsamo and Clément Albergel for providing soil moisture data of ERA-Land.

Edited by: E. Zehe

\section{References}

Albergel, C., de Rosnay, P., Gruhier, C., Muñoz-Sabater, J., Hasenauer, S., Isaksen, L., Kerr, Y., and Wagner, W.: Evaluation of remotely sensed and modelled soil moisture products using global ground-based in situ observations, Remote Sens. Environ., 118, 215-226, 2012.

Alonistioti, D.: Investigation of forest fire impact on the hydrological response of river basins in Eastern Attica region, Master Thesis, Inter-Departmental Postgraduate Course Water Resources Science and Technology, National Technical University of Athens, 2011.

Aronica, G. and Candela, A.: A Regional Methodology for Deriving Flood Frequency Curves (FFC) in Partially Gauged Catchments with Uncertain Knowledge of Soil Moisture Conditions, in: Proc. iEMSs 2004, University of Osnabru, Germany, 1147 1183, 2002. 
Balsamo, G., Albergel, C., Beljaars, A., Boussetta, S., Brun, E., Cloke, H., Dee, D. Dutra, E., Pappenberger, F., de Rosnay, P., Muñoz Sabater, J., Stockdale, T., and Vitart, F.: ERAInterim/Land: A global land-surface reanalysis based on ERAInterim meteorological forcing, Era Report series: European Centre for Medium Range Weather Forecasts - ECWMF, Shinfield Park, Reading, Berkshire, RG2 9AX, England, 13, p. 25, 2012.

Balsamo, G., Albergel, C., Beljaars, A., Boussetta, S., Cloke, H., Dee, D., Dutra, E., Muñoz-Sabater, J., Pappenberger, F., de Rosnay, P., Stockdale, T., and Vitart, F.: ERA-Interim/Land: a global land water resources dataset, Hydrol. Earth Syst. Sci. Discuss., 10, 14705-14745, doi:10.5194/hessd-10-14705-2013, 2013.

Barredo, J. I.: Major flood disasters in Europe: 1950-2005, Nat. Hazards, 42, 125-148, 2006.

Bartalis, Z., Wagner, W., Naeimi, V., Hasenauer, S., Scipal, K., Bonekamp, H, Figa, J., and Anderson, C.: Initial soil moisture retrievals from the METOP-A advanced Scatterometer (ASCAT), Geophys. Res. Lett., 34, L20401, doi:10.1029/2007GL031088, 2007.

Beck, H. E., de Jeu, R. A. M., Schellekens, J., van Dijk, A. I. J. M., and Bruijnzeel, L. A.: Improving Curve Number Based Storm Runoff Estimates Using Soil Moisture Proxies, Selected Topics in Applied Earth Observations and Remote Sensing, IEEE J. Select. Topics Appl. Earth Observ. Rem. S., 2, 250-259, doi:10.1109/JSTARS.2009.2031227, 2009.

Berthet, L., Andréassian, V., Perrin, C., and Javelle, P.: How crucial is it to account for the antecedent moisture conditions in flood forecasting? Comparison of event-based and continuous approaches on 178 catchments, Hydrol. Earth Syst. Sci., 13, 819831, doi:10.5194/hess-13-819-2009, 2009.

Beven, K.: A manifesto for the equifinality thesis, J. Hydrol., 320, 18-36, 2006.

Brocca, L., Melone, F., and Moramarco, T.: On the estimation of antecedent wetness conditions in rainfall - runoff modelling, Hyrol. Process., 642, 629-642, 2008

Brocca, L., Melone, F., Moramarco, T., and Singh, V. P.: Assimilation of Observed Soil Moisture Data in Storm Rainfall-Runoff Modeling, J. Hydraul. Eng., 2, 153-165, 2009a.

Brocca, L., Melone, F., and Moramarco, T.: Antecedent Wetness Conditions based on ERS scatterometer data in support to rainfall-runoff modeling, J. Hydrol., 364, 73-86, 2009b.

Brocca, L., Melone, F., Moramarco, T., Wagner, W., Naeimi, V., Bartalis, Z., and Hasenauer, S.: Improving runoff prediction through the assimilation of the ASCAT soil moisture product, Hydrol. Earth Syst. Sci., 14, 1881-1893, doi:10.5194/hess-141881-2010, 2010.

Brocca, L., Melone, F., Moramarco, T., and Wagner, W.: What perspective in remote sensing of soil moisture for hydrological applications by coarse-resolution sensors, in: Proc SPIE, Vol. 8174, edited by: Christopher, M. U., Neale and Antonino Maltese, September 2011, Prague, Czech Republic, 2011a.

Brocca, L., Melone, F., and Moramarco, T.: Distributed rainfallrunoff modelling for flood frequency estimation and flood forecasting, Hydrol. Process., 25, 2801-2813, 2011 b.
Brocca, L., Hasenauer, S., Lacava, T., Melone, F., Moramarco, T., Wagner, W., Dorigo, W., Matgen, P., Martinez-Fernández, J., Llorens, P., Latron, J., Martin, C., and Bittelli, M.: Soil moisture estimation through ASCAT and AMSR-E sensors: an intercomparison and validation study across Europe, Remote Sens. Environ., 115, 3390-3408, doi:10.1016/j.rse.2011.08.003, 2011c.

Brocca, L., Melone, F., Moramarco, T., and Wagner, W.: A new method for rainfall estimation through soil moisture observations, Geophys. Res. Lett., 40, 853-858, 2013.

Camici, S., Tarpanelli, A., Brocca, L., Melone, F., and Moramarco, T.: Design soil moisture estimation by comparing continuous and storm-based rainfall-runoff modeling, Water Resour. Res., 47, W05527, doi:10.1029/2010WR009298, 2011.

Ceballos, A., Scipal, K., Wagner, W., and Martínez-Fernández, J.: Validation of ERS scatterometer-derived soil moisture data in the central part of the Duero Basin, Spain, Hydrol. Process., 19 1549-1566, 2005.

Coccia, G., Mazzetti, C., Ortiz, E. A., and Todini, E.: Application of the TOPKAPI model within the DMIP 2 project, Proceedings of the International Conference, 23rd Conference on Hydrology, Phoenix, Arizona, 2009.

Coustau, M., Bouvier, C., Borrell-Estupina, V., and Jourde, H.: Flood modelling with a distributed event-based parsimonious rainfall-runoff model: case of the karstic Lez river catchment, Nat. Hazards Earth Syst. Sci., 12, 1119-1133, doi:10.5194/nhess-12-1119-2012, 2012.

Dee, D. P., Uppala, S. M., Simmons, A. J., Berrisford, P., Poli, P., Kobayashi, S., Andrae, U., Balmaseda, M. A., Balsamo, G., Bauer, P., Bechtold, P., Beljaars, A. C. M., van de Berg, L., Bidlot, J., Bormann, N., Delsol, C., Dragani, R., Fuentes, M., Geer, A. J., Haimberger, L., Healy, S. B., Hersbach, H., Hólm, E. V., Isaksen, L., Kållberg, P., Köhler, M., Matricardi, M., McNally, A. P., Monge-Sanz, B. M., Morcrette, J.-J., Park, B.-K., Peubey, C., de Rosnay, P., Tavolato, C., Thépaut, J.-N., and Vitart, F.: The ERA-Interim reanalysis: configuration and performance of the data assimilation system, Q. J. Roy. Meteorol. Soc., 137, 553597, 2011.

de Rosnay P., Drusch, M., Vasiljevic, D., Balsamo, G., Albergel, C., and Isaksen, L.: A Simplified Extended Kalman Filter for the Global Operational Soil Moisture Analysis at ECMWF, Q. J. Roy. Meteorol. Soc., 139, 1199-1213, 2013.

Dorigo, W. A., Wagner, W., Hohensinn, R., Hahn, S., Paulik, C., Xaver, A., Gruber, A., Drusch, M., Mecklenburg, S., van Oevelen, P., Robock, A., and Jackson, T.: The International Soil Moisture Network: a data hosting facility for global in situ soil moisture measurements, Hydrol. Earth Syst. Sci., 15, 1675-1698, doi:10.5194/hess-15-1675-2011, 2011.

FAO/UNESCO: Digital Soil Map of the World and Derived Soil Properties, Version 3.6, CD-ROM, Information Division, http: //www.fao.org/ag/agl/agll/dsmw.stm, FAO, Viale delle Terme di Caracalla, 00100 Rome, Italy, 2003.

Graeff, T., Zeher, E., Blume, T., Francke, T., and Schröder, B.: Predicting event response in a nested catchment with generalized linear models and a distributed watershed model, Hydrol. Process., 26, 3749-3769, 2012. 
Gupta, V. and Waymire, C.: A representation of an instantaneous unit hydrograph from geomorphology, Water Resour. Res., 16, 855-862, 1980.

IPCC: Climate Change 2001: Impacts, adaptation and vulnerability, Contribution of Working Group II to the Third Assessment Report of the Intergovernmental Panel on Climate Change, edited by: McCarthy, J. J., Canziani, O. F., Leary, N. A., Dokken, D. J., and White, K. S., Cambridge University Press, Cambridge, UK, and New York, USA, 2001

Jacobshagen, V.: Geologie von Griechenland, Beiträge zur regionalen Geologie der Erde, Gebrüder Borntraeger, Berlin, 1986.

Kerr, Y. H., Waldteufel, P., Wigneron, J.-P., Delwart, S., Cabot, F., Boutin, J., Escorihuela, M.-J., Font, J., Reul, N., Gruhier, C., Juglea, S. E., Drinkwater, M. R., Hahne, A., Martin-Neira, M., and Mecklenburg, S.: The SMOS Mission: New Tool for Monitoring Key Elements ofthe Global Water Cycle, Proc. IEEE, 98, 666687,2010

Kim, N. W. and Lee, J.: Temporally weighted average curve number method for daily runoff simulation, Hydrol. Process., 4948, 4936-4948, 2008.

Matgen, P., Heitz, S., Hasenauer, S., Hissler, C., Brocca, L., Hoffmann, L., Wagner, W., and Savenije, H. H. G.: On the potential of METOP ASCAT-derived soil wetness indices as a new aperture for hydrological monitoring and prediction: a field evaluation over Luxembourg, Hydrol. Process., 26, 2346-2359, 2012.

Melone, F., Neri, N., Morbidelli, R., and Saltalippi, C. A conceptual model for flood prediction in basins of moderate size, in: Applied simulation and modeling, edited by: Hamza, M. H., IASTED Acta Press, California, 461-466, 2001.

Melone, F., Corradini, C., and Singh, V. P.: Lag prediction in ungauged basins: an investigation through actual data of the upper Tiber River valley, Hydrol. Process., 16, 1085-1094, doi:10.1002/hyp.313, 2002.

Montaldo, N., Rondena, R., Albertson, J. D., and Mancini, M.: Parsimonious modelling of vegetation dynamics for ecohydrological studies of water-limited ecosystems, Water Resour. Res., 41, W10416, doi:10.1029/2005WR004094, 2005.

Moramarco, T., Melone, F., and Singh, V. P.: Assessment of flooding in urbanized ungauged basins: a case study in the Upper Tiber area - Italy, Hydrol. Processe., 19, 1909-1924, 2005.

NOA - National Observatory of Athens: The network of automatic meteorological stations of the National Observatory of Athens, Athens, September 2012.

Owe, M., De Jeu, R. and Walker, J.: A methodology for surface soil moisture and vegetation optical depth retrieval using the microwave polarization difference index, IEEE T. Geosci. Remote, 39, 1643-1654, 2001.

Owe, M., De Jeu, R., and Holmes, T.: Multisensor historical climatology of satellite-derived global land surface moisture, J. Geophys. Res., 113, F01002, doi:10.1029/2007JF000769, 2008.

Papathanasiou, C., Safiolea, E., Makropoulos, C., and Mimikou, M.: The FLADAR Project and its contribution to the implementation of the EU Flood Directive 2007/60, Proc. 11th International Conference on Environmental Science and Technology, 3-5 September, Chania, Crete, Greece, 2009.

Papathanasiou, C., Alonistioti, D., Kasella, A., Makropoulos, C., and Mimikou, M.: The impact of forest fires on the vulnerability of peri-urban catchments to flood events (The case of the Eastern
Attica region), Global NEST J. Hydrol. Water Resour., 14, 294 302, 2012.

Papathanasiou, C., Makropoulos, C., Baltas, E., and Mimikou, M.: The Hydrological Observatory of Athens: A state-of-the-art Network for the Assessment of the Hydrometeorological Regime of Attica, 13th International Conference on Environmental Science and Technology (CEST 2013), 5-7 September 2013, Athens, Greece, 2013.

Paquet, E., Garavaglia, F., Garçon, R., and Gailhard, J.: The SCHADEX method: A semi-continuous rainfall-runoff simulation for extreme flood estimation, J. Hydrol., 495, 23-37, 2013.

Penna, D., Tromp-van Meerveld, H. J., Gobbi, A., Borga, M., and Dalla Fontana, G.: The influence of soil moisture on threshold runoff generation processes in an alpine headwater catchment, Hydrol. Earth Syst. Sci., 15, 689-702, doi:10.5194/hess-15-6892011, 2011.

SCS - Soil Conservation Service: Hydrology, National Engineering Handbokk, Supplement A, Section 4, Soil Conservation Service, USDA, Washington, D.C., 1993.

Todini E. History and perspective of hydrological catchment modelling, in: Water, Environment, Energy and Society, edited by: Jain, S. K., Singh, V. P., Kumar, V., Kumar, R., Singh, R. D., and Sharma, K. D., Proc. of WEES-2009, Allied Publishers Pvt. Ltd, New Delhi, India, 512-523, 2009.

Tramblay, Y., Bouvier, C., Martin, C., Didon-Lescot, J.-F., Todorovik, D., and Domergue, J.-M.: Assessment of initial soil moisture conditions for event-based rainfall-runoff modelling, J. Hydrol., 387, 176-187, 2010.

Tramblay, Y., Bouvier, C., Ayral, P.-A., and Marchandise, A.: Impact of rainfall spatial distribution on rainfall-runoff modelling efficiency and initial soil moisture conditions estimation, Nat. Hazards Earth Syst. Sci., 11, 157-170, doi:10.5194/nhess-11157-2011, 2011.

Tramblay, Y., Bouaicha, R., Brocca, L., Dorigo, W., Bouvier, C., Camici, S., and Servat, E.: Estimation of antecedent wetness conditions for flood modelling in northern Morocco, Hydrol. Earth Syst. Sci., 16, 4375-4386, doi:10.5194/hess-16-43752012, 2012.

Van Steenbergen, N. and Willems, P.: Increasing River Flood Preparedness by Real-time Warning Based on Wetness State Conditions, J. Hydrol., 489, 227-237, 2013.

Viviroli, D., Mittelbach, H., Gurtz, J., and Weingartner, R.: Continuous simulation for flood estimation in ungauged mesoscale catchments of Switzerland - Part II: Parameter regionalisation and flood estimation results, J. Hydrol., 377, 208-225, 2009.

Wagner, W., Lemoine, G., and Rott, H.: A Method for Estimating Soil Moisture from ERS Scatterometer and Soil Data, Remote Sens. Environ., 4257, 191-206, 1999.

Wagner, W., Hahn, S., Kidd, R., Melzer, T., Bartalis, Z., Hasenauer, S., Figa, J., de Rosnay, P., Jann, A., Schneider, S., Komma, J., Kubu, G., Brugger, K., Aubrecht, C., Zuger, J., Gangkofner, U., Kienberger, S., Brocca, L., Wang, Y., Bloeschl, G., Eitzinger, J., Steinnocher, K., Zeil, P., and Rubel, F.: The ASCAT soil moisture product: specifications, validation results, and emerging applications, Meteorol. Z., 22,. 5-33, 2013.

Younis, J., Anquetin, S., and Thielen, J.: The benefit of highresolution operational weather forecasts for flash flood warning, Hydrol. Earth Syst. Sci., 12, 1039-1051, doi:10.5194/hess-121039-2008, 2008. 